Title: Regionally-based medical practitioners may need support when prescribing exercise to pregnant women.

Running title: Practitioners and exercise during pregnancy.

Authors:

1. Melanie Hayman M.Ed (Corresponding Author)

PhD Candidate

School of Medical and Applied Sciences

Central Queensland University, Bruce Highway, Rockhampton, QLD 4702

Email: m.j.hayman@cqu.edu.au Phone: 0749309720

2. Dr Camille Short (PhD)

NHMRC ECR Fellow

Freemasons Foundation Centre for Men's Health

Faculty of Health Sciences

The University of Adelaide, North Terrace, Adelaide

Email: camille.short@adelaide.edu.au

3. Dr Peter Reaburn (PhD)

School of Medical and Applied Sciences

Central Queensland University, Bruce Highway, Rockhampton, QLD 4702

Email: p.reaburn@cqu.edu.au

Author Contributions: MH and PR designed the study. MH and CS analysed results. MH drafted the manuscript. PR and CS critically reviewed the manuscript and assisted with revisions. All authors read and approved the final manuscript, and take responsibility for the integrity of the data.

I state that the contents are the authors' original work and that the paper has not been submitted for publication to another journal.

"Competing interests: No relevant disclosures"

This is the author manuscript accepted for publication and has undergone full peer review but has not been through the copyediting, typesetting, pagination and proofreading process, which may lead to differences between this version and the Version of Record. Please cite this article as doi: $\underline{10.1111 / a j r .12293}$

This article is protected by copyright. All rights reserved 
Revised Date : 10-Feb-2016

4

Accepted Date : 17-Feb-2016

Article type : Short Report

6

8 Regionally-based medical practitioners may need support when prescribing exercise 9 to pregnant women.

Introduction: Physical activity (PA) undertaken in accordance with exercise during pregnancy guidelines is associated with a variety of health benefits. ${ }^{1}$ Despite these health benefits, very few women are sufficiently active during pregnancy. ${ }^{1}$ International research suggests that medical practitioners (MP) play a vital role in assisting women to exercise during pregnancy, with exercise counselling by MPs found to be effective and feasible in increasing PA levels in pregnant women. ${ }^{2}$

An increase in visits to MPs during pregnancy places MPs in a unique position to offer consistent PA/exercise counselling and support. ${ }^{2}$ Specifically, pregnant women see their MP up to 11 times over the course of an uncomplicated pregnancy, ${ }^{2}$ compared to the general population who see their MP at least once a year. ${ }^{3}$ Furthermore, MP advice is a powerful motivator to increase PA levels because of the MPs perceived credibility and authority ${ }^{4}$, especially among pregnant women who may consider pregnancy as the opportune time to implement healthy lifestyle changes. However, previous research suggests MPs may not be promoting exercise in accordance with recommended guidelines, or utilising screening tools to assist in the exercise prescription process.

International research also suggests that MPs receive no formal training in exercise prescription for pregnant women and that many MPs lack confidence in their exercise counselling abilities and knowledge. ${ }^{2}$ However, no study to date has 
examined these factors in an Australian context. The importance of having MPs provide PA/exercise advice is amplified in rural, remote and regional Australia where PA levels are lowest, and access to specialist healthcare services, such as antenatal care, is less accessible than in urban Australia. ${ }^{5}$ These factors place individuals living in rural, regional and remote areas of Australia at increased health risk. ${ }^{5}$ Thus, interventions that aim to increase PA through MP counselling are warranted. To inform intervention development, insight into what MPs currently know about exercise during pregnancy is needed. The current study aimed to examine the level of awareness of exercise during pregnancy guidelines and associated screening tools, training received, and degree of confidence in offering exercise prescription to pregnant women in a sample of MPs based in Rockhampton, Australia. This study was approved by the CQUniversity Human Research Ethics Committee (H13/06-123).

Participants, Methods \& Results: All GPs in Rockhampton ( $\mathrm{n}=80-90)$ were invited to participate in a survey exploring level of awareness of exercise during pregnancy guidelines and associated screening tools, what training MPs received in exercise prescription for pregnant women, and MPs confidence in prescribing exercise to pregnant women. Of these, 50 responded (response rate 55-62\%). Most participants were female (58\%), aged 25-34yrs (40\%) and practicing less than 5 years (40\%). Only $8 \%$ were familiar with exercise during pregnancy guidelines and none were familiar with screening tools. Only $4 \%$ of MP's had received formal training in exercise prescription while $42 \%$ were confident in providing exercise advice to pregnant women. Results are further illustrated in Table 1.

Comment: The present findings suggest Rockhampton-based MPs in Australia have insufficient awareness of exercise during pregnancy guidelines and associated screening tools, receive very little formal training in prescribing exercise to pregnant women and lack confidence in providing exercise prescription to pregnant women. There are obvious advantages to having MPs offer exercise advice to pregnant women, especially in a regional setting where access to specialist services may be limited. To do this, MPs need to be equipped with the necessary training and ongoing support to provide effective exercise prescription to pregnant women. Future studies 
60 using nationally representative samples are needed to better inform both policy and 61 practice.

62

63 KEY WORDS: Physical activity, exercise, pregnancy, maternal health, primary care

64

65 Conflicts of Interest

66 None declared.

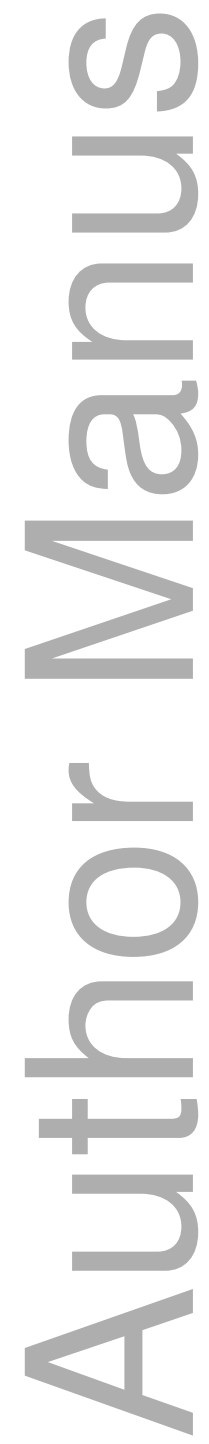

This article is protected by copyright. All rights reserved 


\section{Reference List}

1. Mudd L, Owe $\mathrm{K}$, Mottola $\mathrm{M}$, et al. Health benefits of physical activity during pregnancy: An international perspective. Medicine and Science in Sports and Exercise. 2012.

2. Joy E, Mottola M, Chambliss H. Integrating exercise is medicine into care of pregnant women. Current Sports Medicine Reports. 2013; 12: 245-7.

3. Australian Bruearu Statistics. Patient experiences in Australia: Summary of findings, 2011-12. Internet. 2014. [cited 2015 October]. ABS cat no, 4839.0]. Available from: http://www.abs.gov.au

4. Andersen R, Blair S, Cheskin L, et al. Encouraging patients to become more physically active: the physician's role. Ann Inten Med. 1997; 127: 395-400.

5. Dobson A, Byles J, Dolja-Gore X, et al. Rural, remote and regional differences in women's health: Findings form the Australian longitudinal study on women's health. Australian Government Department of Health and Ageing. 2011: 1-134.

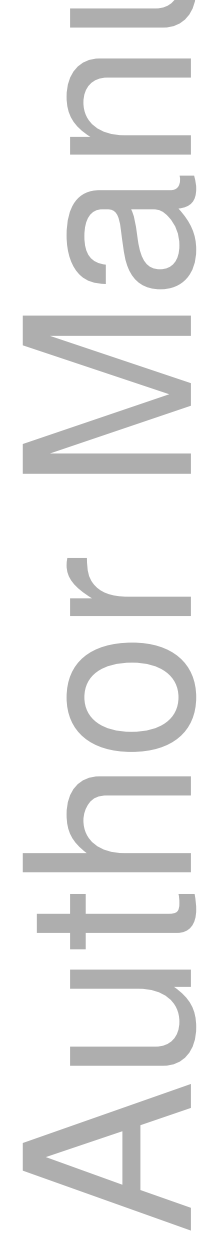


Table 1. Training, awareness and confidence in providing exercise advice to pregnant women

\begin{tabular}{|l|c|c|}
\hline \multicolumn{1}{|c|}{ Question } & \multicolumn{2}{c|}{ Response n (\%) } \\
\cline { 2 - 3 } & Yes & No \\
\hline $\begin{array}{l}\text { Have you received any formal training on exercise during } \\
\text { pregnancy? }\end{array}$ & $2(4)$ & $48(96)^{*}$ \\
\hline $\begin{array}{l}\text { Are you familiar with any exercise during pregnancy } \\
\text { guidelines? }\end{array}$ & $4(8)$ & $46(92)^{*}$ \\
\hline $\begin{array}{l}\text { Are you familiar with any screening tools that help to } \\
\text { prescribe exercise among pregnant women? }\end{array}$ & $0(0)$ & $50(100)^{*}$ \\
\hline $\begin{array}{l}\text { Are you confident in providing exercise advice to your } \\
\text { pregnant patients? }\end{array}$ & $21(42)$ & $29(58)$ \\
\hline
\end{tabular}

* Significance $(\mathrm{p}<0.05)$

This article is protected by copyright. All rights reserved 


\section{University Library}

\section{- $\mathrm{M}$ IIN E R VA A gateway to Melbourne's research publications}

Minerva Access is the Institutional Repository of The University of Melbourne

Author/s:

Hayman, M;Short, C;Reaburn, $\mathrm{P}$

Title:

Regionally based medical practitioners may need support when prescribing exercise to pregnant women

Date:

2017-02-01

Citation:

Hayman, M., Short, C. \& Reaburn, P. (2017). Regionally based medical practitioners may need support when prescribing exercise to pregnant women. AUSTRALIAN JOURNAL OF RURAL HEALTH, 25 (1), pp.62-63. https://doi.org/10.1111/ajr.12293.

Persistent Link:

http://hdl.handle.net/11343/291196 